\title{
Cellulose ethers influence on water retention and consistency in cement-based mortars
}

\section{Laetitia Patural(1), PhilipPe MARChal(2), Alexandre Govin(1)*, PhilipPe GROSSEAU ${ }^{(1)}$, BERTRAND RUOT ${ }^{(3)}$, OLIVIER DEVÈS ${ }^{(3)}$}

(1) Ecole Nationale Supérieure des Mines de Saint Etienne ; Centre SPIN ; Département PMMC ; LPMG-UMR CNRS 5148 ; 158 Cours Fauriel, 42023 Saint-Étienne Cedex 2, France

(2) Laboratoire de Réactions et Génie des Procédés (LRGP-UPR CNRS 3349), Centre de Génie Chimique des Milieux Rhéologiquement Complexes (GEMICO), 1 rue Grandville, BP 20451, 54001 Nancy Cedex, France

(3) Université Paris-Est, Centre Scientifique et Technique du Bâtiment, Département Enveloppe et Revêtements/Division Enduits, Mortiers et Colles, 84 avenue Jean Jaurès, 77447 Marne-la-Vallée Cedex 2, France

\begin{abstract}
Cellulose ethers (CE) are commonly used as additives to improve the quality of cement-based materials. As admixtures, they improve the properties of mortars such as water retention, workability, and open time. Also, polysaccharides such as starch derivatives are used to improve the consistency of the fresh material.

The properties of cement-based mortars at fresh state were investigated. The effect of CE and their physico-chemical parameters (molecular weight, substitution degrees, etc.) on both water retention and rheological properties of mortars were studied. Moreover, some starch derivatives were also examined in order to better understand the water retention mechanisms.

Rheological measurements showed that CE have a thickening effect for a content of 0.27 wt.\%. Besides, a fundamental effect of CE molecular weight on mortar consistency and its water retention capability was highlighted. Finally, the comparison with starch ethers proved that, for those admixtures, water retention is not directly linked to mortar's viscosity.

Keywords:

Cellulose ether (D); Consistency (A); Freshly-mixed mortar (A); Starch ether (D); Water retention $(C)$
\end{abstract}

\section{Introduction}

Factory-made mortars have been mostly implemented as masonry renderings, fixing tiles, self-levelling floors and so on. When mortar is applied on substrate, water may be absorbed by the substrate. This phenomenon can induce insufficient hydration of cement, and thus decrease mechanical properties of the mortar. Water retention capacity of a mortar is thus a key element when choosing an appropriate formulation as a function of the substrate, climatic conditions, and industrial applications of the mortar, etc, ...

A wide variety of chemical admixtures are present in industrial mortars currently used in construction. They are classified according to the function they perform, e.g. air entrainment, water retention, set retardation or acceleration, etc, ...[1] Among the organic admixtures

\footnotetext{
"Corresponding author: govin@emse.fr
} 
widely used in mortar and concrete, polysaccharides are polymers that can be classified as water reducer, set retarder, anti-washout and water retention agent [1] and [2]. Many authors demonstrated that mortar and concrete properties can significantly be modified at both the fresh and hardened states by the addition of polysaccharides [3], [4], [5] and [6]. Among all polysaccharides, cellulose ethers are commonly introduced into industrial mortar formulations in order to provide some required properties to the mortar, from the fresh paste to the hardened material [7]. These cellulose derivatives are suitable molecules to improve water retention and workability of the fresh material, together with adhesion to the substrate [3]. However, the major drawback of these macromolecules in mortar formulation is the cement hydration delay [2], [6] and [8]. Pourchez et al. highlighted various delays on cement hydration induced by cellulose ethers (from $10 \mathrm{~min}$ up to several hours) [9] and [10]. This delay seemed to mainly depend on the chemical structure of the molecule and, in particular, on the degree of substitution.

When the support material absorbs water, this can induce insufficient hydration of the cement and therefore provoke a loss in mechanical performances. Water retention is a mortar property that prevents the rapid loss of water to the substrate by suction. This property avoids bleeding or "water loss" when the mortar is in contact with relatively permeable surfaces. Water retention is a fundamental property, which affects workability and bonds between mortar and masonry. Water-retaining agents, also known as thickening or viscosity enhancing additives, are essential components in mortar formulation because they also reduce segregation and improve workability. However, they can slightly reduce compressive strength of the hardened concrete depending on the W/C [2], [11], [12] and [13]. The most widespread cellulose ethers used in practice as admixtures are hydroxypropyl methyl cellulose (HPMC) and hydroxyethyl methyl cellulose (HEMC) [2] and [11]. Some publications deal with HEMC and with other organic additives such as latexes mixed with a silicone emulsion, and starches [14], [15] and [16]. They showed that mortar water retention capacity is improved thanks to these admixtures. This property is also increased with a rise in polymer to cement ratio. Moreover, Pourchez et al. studied the influence of a few HEMC and HPMC on water retention capacity and their results revealed the significant influence of the admixture molecular weight [9]. However, a better understanding of the admixture-cement interactions is required to explain this water retention enhancement.

An assumption usually proposed to explain the water retention capacity of cellulose ethers involves an increase of mortar viscosity [17]. This hypothesis needs further verifications of the mortar consistency effect on water retention. Cellulose ethers can bring about excellent water retention thanks to a possible superposition of two phenomena. Pourchez ventured two hypotheses: (i) a rheological effect similar to those produced by other polysaccharides; (ii) an effect that could be inherent to cellulose ethers, such as a modification of the porous network in the fresh state, osmotic pressure, or the presence of a cellulose ether film playing the role of diffusion barrier [18]. Jenni et al. investigated the role of one type of HEMC on changes in mortar microstructures [19]. They proposed that the air entrapped during mixing process was stabilised by cellulose ethers (due to decrease of the surface tension of the water). Moreover, they showed that cellulose ethers films were frequently observed between two juxtaposed air voids and also along the pore wall of a single air void.

The rheological properties of fresh concrete are related to cement hydration and chemical interactions in the cement paste system [20]. The concrete's flow properties such as the relationship between shear rate and viscosity are the subject of ongoing researches. Many simplified methods are used to estimate rheological properties and are well correlated to the rheological parameters (yield stress, plastic viscosity). Ferraris gave an overview of the commonly tests (14 test methods) used to characterize concrete rheology, including slump, penetration, Tattersal two-point tests, etc, ... [21] Rheological studies were executed on admixed cement-based mortars. Seabra et al. showed that the use of admixtures, such as water-retaining, plasticizer and air entraining, considerably changed the rheological behaviour of admixed lime-based mortars [22] and [23]. In particular, the introduction of a water-retaining agent promoted thickening followed, after agitation, by thinning because air 
was entrained into the mortar. Paiva et al. demonstrated that HPMC thickened the mortar due to an increase of the plastic viscosity. HPMC promoted cohesion among the material particles at fresh state [24]. Nevertheless, the effect of CE structural parameters on the rheological properties of cement-based mortars is still not well understood.

This study aims to identify the main CE parameters which control the water retention of cement-based materials. Secondly, this paper investigates the relationship between rheological behaviour of a mortar and its capacity to retain water in order to go into details with the hypothesis that both properties are linked together.

Our exploration of water retention mechanisms in CE-admixed mortars proceeds as follows. First, a set of chemical admixtures was selected to study the impact of the average molecular weight and molar substitution $(M S)$ on rheological properties and water retention of mortars. Samples had identical chemical structure and only differed by their molecular weights or $M S$. Beforehand, a characterization of all admixtures was performed to quantify their molecular mass. Then, the rheological behaviour was evaluated using rheometry (i.e. yield stress, flow behaviour index and consistency coefficient). Afterwards, the influence of these physicochemical parameters on mortar water retention capacity and its rheological behaviour were studied. Finally, the effect of some starch derivatives was investigated and compared to the results of CE.

\section{Materials and experimental methods}

\section{II.1. Mineral products}

Mortars were prepared according to the CEReM (consortium for study and research on mortars) mixture proportions shown in Table 1 [7]. Mixing procedure was in accordance with EN 196-1 [25]. Admixture amount (0.27\%) was in addition to the total dry mixture (i.e. cement, sand and filler). Sand was siliceous and conformed to NF EN 13139 Standard [26] [26], its reference was DU 0.1/0.35. The filler was calcium carbonate $\left(\mathrm{CaCO}_{3}\right)$. Portland cement CEM I 52.5 R was employed, according to EN 197-1 [27]. Chemical analysis was accomplished by X-ray fluorescence spectroscopy (XRF). Then, approximate phase proportions were calculated using Bogue's formula, with a correction on $\mathrm{CaO}$ due to sulfates. The composition of the cement is presented in Table 2. Each experiment was performed three times with the results averaged.

\section{II.2. Organic admixtures}

Admixtures are specially prepared products that are added in small amounts to mortar during the mixing process in order to improve its properties.

\section{II.2.1. Starch ethers}

Starch is a naturally high-polymeric carbohydrate composed of glucopyranose units bonded together by a-glucosidic linkages. Starch is made up of a linear polymer (amylose) and a branched polymer (amylopectin). Starch ethers are obtained by the reaction of alkyl groups with etherifying agents. In this study, seven starch ethers (SE) were used: two carboxymethyl-hydroxypropyl starches (M1 and M4) and four hydroxypropyl starches (M2, M3, L2 and L3). Properties of the studied starch ethers are detailed in Table 3.

In construction industry, starch ethers enhance workability and improve the application properties of building products.

\section{II.2.2. Cellulose ethers}

Cellulose, the most abundant polymer in Nature, occurs mainly within the cell walls of higher plants as a structural material. It is a polysaccharide composed 1,4 glycosidic bonds.-of individual anhydroglucose units linked through $\beta$ Because of the strong hydrogen bonds that occur between cellulose chains, cellulose does not melt or dissolve into common solvents. Substitution of hydroxyl groups within the cellulose backbone by functional groups provides cellulose with water-solubility through the decrease in the crystallinity of the molecule. The addition of these other groups produces cellulose derivatives like methyl, hydroxyethyl, hydroxypropylmethyl celluloses. In this paper, three kinds of cellulose ethers (CE) were 
studied: three panels of hydoxyethyl methyl cellulose (HEMC, named as C and TV), two panels of hydoxypropyl methyl cellulose (HPMC, named as $\mathrm{J}$ and P), two panels of hydoxyethyl cellulose (HEC, named as $\mathrm{H}$ and $\mathrm{N}$ ). These three $\mathrm{CE}$ families are drawn on Figure 1, where substituent positions are arbitrary; they differ from one molecule to another. While the focus of our work is on adding HEMC, HPMC, or HEC to mortars, it is interesting to note that these cellulose derivatives are beneficial and widely used in many industrial fields such as foods, cosmetics, pharmaceuticals, latex paints, construction products, ceramics, and so on. In building domain, cellulose products are used as water retention agents, thickeners, binders, and film formers. To investigate the structural parameter effects, $24 \mathrm{CE}$ were selected (Table 3). Cellulose ethers are defined by three parameters: the average molecular mass $\left(M_{\mathrm{w}}\right)$ and two substitution degrees. The number of substituted hydroxyl groups per anhydroglucose unit is expressed as $D S$ (degree of substitution). Moreover, the molar ratio of alkoxy groups in the side chains to cellulose is expressed as the average molar substitution $(M S)$ [28].

HEMC C compounds have a constant chemical structure except for $\mathrm{C} 1$; it varies slightly in methoxyl percentage (Table 3). Hence, only the influence of weight average molecular mass on water retention was studied. In the same manner, the molecular weight effect was examined with HMPC J and HEC $\mathrm{N}$ for which the substitution degrees are constant among the respective groups. HEMC TV and HPMC P families allowed the investigation of molar substitution impact on mortar's properties.

\section{II.3. Characterization of admixtures}

All polysaccharides were characterized by Size Exclusion Chromatography (SEC) in order to obtain their average molecular weight [9], [29] and [30]. SEC analysis was performed on a Waters apparatus equipped with a pump (Waters 916) and a refractometer-type detector (Waters 2410). To study CE and SE, two different columns were used which were the Tosohaas TSK Gel GMPWXL and the OHpak SB-806 M HQ respectively. In our case, the eluent was a $0.5 \mathrm{~mol} \mathrm{~L}^{-1}$ sodium chloride solution, it, was filtered and on line-degassed. The flow rate was set to $0.5 \mathrm{~mL} \mathrm{~min}^{-1}$ and the column was kept at $35^{\circ} \mathrm{C}$ in an oven.

Calibration was performed using standard molecules with known molecular weight and a theoretical polydispersity index close to 1 . The obtained peaks established the calibration curve by drawing $\ln \left(\bar{M}_{W}\right)$ versus the retention time. Subsequently, every chromatogram was divided into slices of $h_{\mathrm{i}}$ in height. Thanks to the calibration curve, every retention time corresponded to a mass $M_{\mathrm{i}}$ of $N_{\mathrm{i}}$ molecules eluted of the studied polymer. Every slice height was directly proportional to the concentration $c_{\mathrm{i}}$ of the eluted polymer. Therefore, the weight average molecular mass (noted as $\bar{M}_{W}$ ) and the number average molecular mass (noted as $\bar{M}_{n}$ ) were calculated thanks to the following equations (Equation (1) and Equation (2)).

$$
\begin{gathered}
\bar{M}_{W}=\frac{\sum c_{i} M_{i}}{\sum c_{i}} \\
\bar{M}_{n}=\frac{\sum c_{i}}{\sum \frac{c_{i}}{M_{i}}}
\end{gathered}
$$

\section{II.4. Water retention measurements}

The water retention capacity can be assessed using different test methods. For example, freshly-mixed mortar can be subjected to suction; thereby simulating the action of an absorptive substrate, and the removed water is measured. 
A standard method to estimate the water retention capacity of a mortar is the test described in ASTM C1506-09 [31]. ASTM measurements had to be performed $15 \mathrm{~min}$ after mixing to measure the water loss of a mortar under depression. The standardised apparatus (Figure 2) was composed of a perforated dish attached to a vacuum assembly by a funnel. The dish was filled in with the freshly-mixed mortar and weighed. The apparatus was exposed to a vacuum of $50 \mathrm{~mm}$ of mercury for $15 \mathrm{~min}$.

Then, the water retention capacity, noted $W R$, was calculated using Equation 3.

$W R(\%)=\frac{W_{0}-W_{1}}{W_{0}} \times 100$

$W_{\mathrm{o}}$ represents the initial mass of mixing water, and $W_{1}$ is the loss of mixing water mass after aspiration.

A second method was also used to measure the water retention, which is the Standard DIN 18555-7 [32]. With this method, the freshly-mixed mortar was in contact with a filter paper, thereby simulating the action of an absorptive substrate. DIN measurements had to be performed $5 \mathrm{~min}$ after mixing. The water retention capacity of a freshly-mixed mortar was characterized by the mass of water it retained after the capillarity action of an absorbent substrate. The standardised apparatus is described in Figure 3. The mortar (3) was poured into the ring. Then, knowing that the water content of the tested mortar was equal to $23 \%$, for CEReM formulation, the water retention was calculated by weight differences:

$W R=100-\frac{W_{f p}}{W_{0}} \times 100$

where $W_{\mathrm{fp}}$ is the quantity of water retained by the filter paper and $W_{\mathrm{o}}$ is the quantity inside the studied mortar.

All tests were carried out at a controlled temperature $\left(23{ }^{\circ} \mathrm{C}\right)$. This parameter had to be controlled as Hucko has shown that water retention and consistency are temperaturedependent [33].

\section{II.5. Rheological measurements}

\section{II.5.1. Apparatus}

The rheological parameters of fresh mortars can be determined by applying a given shear rate and measuring the resulting shear stress. A Rheometrics Fluid Spectrometer RSF II was used in experimental testing.

The fresh mortar was placed into a cylindrical vessel. The rheometer was equipped with vane geometry to measure the rheological properties of the mortar. Previous experiments showed that the vane was adequate for the characterisation of cementitious systems [34]. However, for some admixed mortars, bleeding phenomena affected the experiments, due to the high water/cement ratio. In consequence, a helical geometry was also used. Both configurations provided minimum gaps around $5 \mathrm{~mm}$. Working within these wide-gap geometries facilitates studying coarse particles (up to $0.5 \mathrm{~mm}$ ). In addition, there were enough particles in the gap to take into account, so that, the properties of the suspension, viewed as a continuum medium, were measured for all the materials studied. As the cylinder rotated, the viscous resistance of the mortar flowing through the blades generated a torque, which was continuously registered. Using Couette analogy, the calibration was performed with silicon oil for both mobiles [35].

Despite the use of mixing-type geometry, some admixtures remained affected by sedimentation. So, in order to put back in suspension the mortars, the samples were systematically submitted to a high shear rate during few seconds before each imposed shear rate. For each mortar, measurements began 5 min after mixing. The material was pre-sheared at $63.1 \mathrm{~s}^{-1}$ during $30 \mathrm{~s}$. This pre-shearing action was intended to create uniform conditions before testing and to limit the effect of sedimentation. Then, the studied shear rate was 
applied (for example $30 \mathrm{~s}^{-1}$ ) during $10 \mathrm{~s}$. An example of the sequence used is depicted in Figure 4.

\section{II.5.2. Curve modelling}

Therefore, in characterizing the fundamental flow properties of a material, the shear stress ( $\tau(\mathrm{Pa}))$ was plotted versus the shear rate $\left(\dot{\gamma}\left(\mathrm{s}^{-1}\right)\right)$. Yahia and Khayat [36] and Nehdi and Rahman [37] performed tests with various models (Bingham, Herschel-Bulkley, Sisko, modified Bingham, Casson, and De Kee models) and concluded that flow properties depended on both material composition and experimental conditions. Cement pastes and some mortars did not follow the linear function of Bingham's Law. Consequently, an improved model to fit the flow curves was developed by Herschel and Bulkley [38]. They proposed a power-law variant of the viscoplastic Bingham model. Larrard et al. [39] used this equation (Equation 5) for concretes because it was the most suitable to describe the experimental rheograms.

$$
\tau=\tau_{0}+K \dot{\gamma}^{n}
$$

$\tau_{0}$ is the yield stress, representing the amount of stress required to initiate or maintain flow. $K$ represents the consistency coefficient $\left(\mathrm{Pa} \mathrm{s}^{\mathrm{n}}\right.$ ), and $n$ is the flow index (no unit). When $n=1$, the formula reduces to the Bingham model. The shear-thinning behaviour is associated with $\mathrm{o}<n<1$, and the unusual shear-thickening behaviour with $n>1$ [40]. When $\tau_{0}<<K \dot{\gamma}^{n}$, Equation 5 can be reduced to the power-law model (Equation 6) [41]:

$$
\tau=K \dot{\gamma}^{n}
$$

In this paper, the Herschel-Bulkley model was chosen to compare admixtures to each other. Rheograms were fitted with the Herschel-Bulkley model as shown on Figure 5. The coefficients of correlation are next to 0.99 for all the studied mortars.

\section{Results and discussion}

\section{III.1. Correlation between ASTM C1506-09 and DIN 18555-7 test methods}

The comparison between both methods is shown on Figure 6. Usually, both methods gave rather close results, except for few molecules. Those were three HEC (N1, N2 and N3) that conferred to the mortar a more liquid aspect. The water retention value obtained with the DIN method was close to 90\% while the result of ASTM was fairly higher (roughly 97\%). This can be explained by a bleeding phenomenon observed for these admixtures during the experiment. Indeed, water seemed to stay above whereas sand is at the bottom.

The ASTM values were generally slightly higher than those obtained with the DIN method. This phenomenon can be explained by a depression effect. Indeed, the ASTM measurement was performed under vacuum $(50 \mathrm{~mm}$ of mercury), while the DIN method was a measurement of absorbed water in contact with a filter paper, based on gravity and performed at atmospheric pressure.

All things considered, the DIN 18555-7 and the ASTM C1506-09 methods are two ways to determine water retention that are comparable. In our paper, only the water retention results obtained with the ASTM method are shown.

\section{III.2. Helical geometry: an unusual way to characterize settling mortars}

To the extent that it generates a vertical pumping, the helical geometry was used to minimize the sedimentation of particles during the rheological test [42]. Such mixer-type geometry belongs to the category of process geometries that allows the possibility to extract rheological information directly from torque-rotor speed measurement in batch or semi-batch configuration, during and at the end of the preparation of a complex liquid-like product. Using a Couette analogy, it has been shown that the torque-rotor speed data can be transformed into shear stress-shear rate curves, which are in fairly good agreement with offline measurements obtained in conventional rheometers [35]. 
In order to validate the experimental procedure, the results obtained by submitting nonsettling samples to a high velocity gradient before each measurement were compared with results obtained in standard steady state regime i.e. without resuspension steps. These experiments were performed using the vane geometry for a large range of CE-admixed mortars.

For example, for HEMC $\mathrm{C}_{3}$ and $\mathrm{C}_{4}$ (Figure 7), results show that the high shear rate steps did not influence significantly the rheological behaviour of the samples. This comparison also demonstrated that the yield stress noted in the case of HEMC $\mathrm{C}_{3}$ in steady state is not a real yield stress; it is most probably due to sedimentation. These results confirm what is observed with the naked eyes.

Then, to validate the use of the helical geometry, a comparison with the vane was realized for CE-admixed mortars that were not subjected to settling. Figure 8 presents a comparison for two HEMC ( $\mathrm{C}_{3}$ and $\left.\mathrm{C}_{4}\right)$ and shows that the rheograms obtained with both geometries are very similar. It confirms that the helical mobile can be used without effect on mortar structure.

In consequence, since it allows a better homogenization of the samples, the helical geometry, associated with the resuspension procedure, was used to perform experiments for settling mortars.

\section{III.3. Effect of molecular weight on rheological parameters and water retention}

In mortar composition, water-retaining agents are commonly used. Indeed, they retain water inside the mortar during the hydration process caused by absorption through the substrate. The water retention capacity will depend on mortar composition.

According to the NF DTU 26.1, mortars can be divided into three classes [43]. The first category (low retention) is for mortars that have water retention lower than $86 \%$. The second class (intermediate retention) corresponds to values ranging from $86 \%$ to $94 \%$. The last one (strong retention) is defined by water retention higher than 94\%. Strong retention corresponds to the values sought for good mechanical properties. These limits only refer to the ASTM C1506-09 measurements. Thus, care must be taken when dealing with them.

\section{III.3.1. HEMC}

HEMC C mainly differs by their molecular weight (Table 3). The presence of these admixtures had a strong influence on the rheological parameters calculated with Herschel Bulkley model. At first, the yield stress values decreased as the HEMC molecular weight increased (Table 4). They ranged from 5.4 $\mathrm{Pa}$ for $\mathrm{C} 1$ to 2.0 $\mathrm{Pa}$ for $\mathrm{C}_{4}$. These values are lower than those found in the literature obtained for mortars containing superplasticizers and stabilizing agents [44] and [45].

Concerning the flow index, Table 4 shows that this parameter decreases from 0.86 for $\mathrm{C} 1$ to 0.59 for $\mathrm{C} 4$. This change over molecular weight means that the samples become more shearthinning as the molecular weight of the HEMC increases.

Finally, the effect of CE molecular weight on mortar water retention and on the consistency coefficient is highlighted in Figure 9. The viscosity of the mortar was improved thanks to the presence of cellulose ether in the continuous phase. The viscosity of this phase increased with a rise in admixture molecular weight.

For a constant chemical structure, experimental results of water retention highlighted the impact of HEMC molecular weight (Figure 9). In spite of $\mathrm{C} 1$ difference, its influence was in line with the three other HEMC. Hence, for HEMC with molecular mass lower than 400,000 Da, the higher the molecular mass, the better the mortar water retention capacity. These results are in accordance with other data reported in literature [9]. Furthermore, $\mathrm{C} 1$ did not provide strong water retention (i.e. lower than 94\%). For very low HEMC molecular weights, the mortar water retention was intermediate (class defined by the NF DTU 26.1). On the contrary, $\mathrm{C}_{2}, \mathrm{C}_{3}$ and $\mathrm{C}_{4}$ provided strong water retention capacities to the mortar (respectively 95.7\%, 96.4\% and 98.8\%).

It is important to note that consistency measurements can also be related to the cellulose ether molecular mass (Figure 9). Mortar consistency is also improved when the polymer molecular weight increases. For this HEMC sample group, both mortar consistency and water 
retention went up when admixture molecular mass increased. Consequently, mortar water retention was plotted versus its consistency. The results are illustrated in Figure 12. For HEMC C, a rise in consistency leads to a similar water retention increase.

\section{III.3.2. HPMC}

The effect of HPMC molecular weight on the properties of the fresh mortar was studied with 3 cellulose ethers, named $\mathrm{J}$ family. These molecules had the same substitution degrees ( $D S=1.8$ and $M S=0.10$ ). Thus, only one parameter varied which was the molecular mass, the studied parameter. The results are shown on Figure 10. An increase of the polymer mass from $225 \mathrm{kDa}$ to $910 \mathrm{kDa}$ leads to an increase of both water retention and consistency coefficient (from $96.8 \%$ to $98.9 \%$ and from 0.6 to 71.5 respectively). Consequently, for HPMC, the conclusions are the same as those established for HEMC: the higher the HPMC molecular weight, the higher the water retention and the consistency.

\section{III.3.3. HEC}

Finally, the effect of the polymer molecular weight was investigated for HEC (Table 3). For that purpose, a group of $7 \mathrm{CE}$ was chosen. This family, named as $\mathrm{N}$, had $M S$ equal to 2.5 for the whole group. The effect of molecular weight is highlighted on Figure 11. Here again, the water retention increased in the same manner as molecular weight. Moreover, a plateau was noticed around $600 \mathrm{kDa}$ from which the retention capacity was constant whatever the CE molecular weight. Nevertheless, the experiment may be not enough discriminatory to observe differences between such strong retention capacities. On the contrary, the consistency coefficient was still increasing among the 7 HEC. For high molecular weights, it seems that the increase in consistency coefficient is less important, indicating the likely presence of a plateau.

In conclusion, for all $\mathrm{CE}$ families of this work, when the $\mathrm{CE}$ molecular weight increases, the yield stress slightly decreases, and at the same time, mortar viscosity is improved and the system becomes more shear-thinning. We can note that there are very weak (HEMC C and HPMC J) or no yield stress values (HEC N). The incorporation of a viscosity enhancing admixture used to increase the yield value, plastic viscosity and apparent viscosity of a cement-based system [2], [37], [46], [47], [48] and [49]. Thus, the yield stress is expected to increase. But, in our situation, we noticed a different evolution concerning the yield stress. In spite of Lachemi et al. studied totally different molecules, our results are in accordance with theirs [12]. Indeed, they reported that the viscosity of the cement paste is increased and the yield stress decreased with the increase of dosages of four new viscosity modifying admixtures from $0.025 \%$ to $0.075 \%$ by weight of cement.

However, it is difficult to compare our results with previous studies because molecules are totally different and sometimes the apparatus is not the same. The effect of cellulose ethers is not well described in the literature. In our situation, $\mathrm{CE}$ effect on yield stress and viscosity can be interpreted as following. When the HEMC molecular weight increased, the polymer is longer thus leading to a best separation of cement particles due to steric hindrance. The CE used to be adsorbed on cement hydrates particles, as a result they coated these cement particles. The associative polymer minimizes contacts between particles and act as a dispersant. Logically, the longer is the polymer, the more coating and dispersant effects are effective and the more the yield stress decreases. However, the molecule is not long enough to bridge cement particles. Moreover, when HEMC is present inside the mortar, a threedimensional gel structure is created due to van der Waals forces and hydrogen bonds [2] and [50]. As the consistency coefficient is concerned, the entanglement of polymer chains increases the viscosity of the continuous phase leading to an increase of the mortar's viscosity.

\section{III.3.4. Relationship between mortar's consistency and its water retention}

Among the CE studied, mortar consistency seems to be correlated with its water retention. On Figure 12, for each CE family, the water retention is stronger for high consistency coefficient values. For example, for HEMC, while the consistency coefficient was multiplied by 46 (from 1.6 to 73 ), water retention capacity was improved by $5.6 \%$ (from $93.6 \%$ to $99.2 \%$ ). This can be explained by the CE capacity to form, when mixed with water, a more or less viscous solution 
[2], [50] and [51]. Consequently, a high molecular mass admixture would lower the viscosity of the mixing water with the result that the water retention would be increased.

However, these results are true within a given family of polymers. As a matter of fact, from one group to another, variations may be noted: for similar consistency coefficient values, water retention results can be different. For example, when HPMC J1 and HEC N1 were compared, their consistency coefficients were similar $\left(\mathrm{K}_{\mathrm{J}_{1}}=0.6\right.$ and $\left.\mathrm{K}_{\mathrm{N} 1}=0.7\right)$ whereas the water retention capacity presented a wide-gap (96.8\% for $\mathrm{J} 1$ and $92.6 \%$ for N1). Those comments also apply for HEMC C1, HPMC N2 and starch ether M2. In fact, the consistency coefficients were around 1.3 for each admixture and the water retention ranged from $85.4 \%$ $(\mathrm{M} 2)$ to $93.6 \%(\mathrm{C} 1)$ and $97.6 \%(\mathrm{~N} 2)$ respectively. Consequently, strong water retention capacities may be only partially explained by the high viscosity of the mortar.

\section{III.4. Effect of starch ether on mortar's properties}

Some starch ethers were also used as counterexamples. These starch derivatives are chosen for cement-based formulations because they improve thickening and smoothness of the fresh material [6] and [52]. First, the rheological behaviour of mortars containing starch ethers was investigated. Figure 13 highlights the bad rheological properties of these admixtures under shear. However, at rest, one can observe that in presence of starch ether, mortar looks like a viscous paste while the non-admixed one is almost liquid.

Nevertheless, these polysaccharides bring important information concerning the relationship between water retention and consistency of mortars. Contrarily to CE, for starch ethers, both parameters evolved in opposite ways: when the consistency coefficient increased, the water retention decreased. As a consequence, a major conclusion of this study is that the water retention of a fresh mortar is not only due to its viscosity.

\section{III.5. Effect of molar substitution on rheological parameters and water retention}

\section{III.5.1. HEMC}

In Table 3, the molar substitution $(M S)$ is the only variable parameter in the HEMC TV groups. Figure 14 shows that $M S$ influence on mortar water retention is weaker than the one of the molecular weight. While the $M S$ is almost multiplied by 5 (from TV1 to TV3), the water retention decreases by only $1 \%$. In the same manner, from TV4 to TV6, the water retention decrease was evaluated to $1.2 \%$. These results demonstrated that for HEMC with molecular weight around $350-400 \mathrm{kDa}$ and $D S=1.8, M S$ had an effect on water retention: the lower the $M S$, the better the water retention. However, compared to the effect of molecular weight, this effect is minor since the maximum gap is $1 \%$.

Nevertheless, the $M S$ impact on the viscosity of the mortar was quite different (Figure 14). As a matter of fact, the consistency coefficient was slightly constant from TV1 to TV3, whereas this parameter increased from TV4 (52.3) to TV6 (72.7). Both curves present a minimum value for intermediate $M S$ (o.11-0.16). Once again, water retention and consistency evolutions can be separated. Thus, another parameter has to be taken into account.

\section{III.5.2. HPMC}

In the same way, the $M S$ effect on the properties of the mortar was investigated with three appropriate HPMC P reported in Table 3. In this panel, both molecular weight and $D S$ are almost constant while $M S$ increases from 0.13 to 0.48 . The results are illustrated in Figure 15. They show that, for a molecular weight around $250 \mathrm{kDa}$ and $D S=1.8$, in the studied $M S$ range, $M S$ has a small effect on water retention capacity. In fact, a $3 \%$-decrease was noticed from $M S=0.13$ to $M S=0.48$. As far the consistency coefficient is concerned, a minimum value was observed when $M S$ equal to 0.22. For these 3 HPMC, both water retention and consistency evolved in the same way.

\section{III.5.3. HEC}

The effect of $M S$ for HEC was studied thanks to HEC N1 and HEC H1. They had equivalent molecular weights whereas $M S$ decreased from 2.5 to 1.9, respectively. Water retention was equal to $93 \%$ for $\mathrm{N} 1$ and to $95 \%$ for H1. Therefore, for constant molecular weight HEC, water 
retention was improved when $M S$ decreased. Nevertheless, both HEC provided the same rheological behaviour to the mortar $\left(\mathrm{K}_{\mathrm{H} 1}=\mathrm{K}_{\mathrm{N}_{1}}=0.7\right)$.

In conclusion, for each $\mathrm{CE}$ group of this study, the molar substitution (relative to hydroxyethyl/hydroxypropyl content) seems to have a weak impact on the water retention of admixed mortars compared to the effects of molecular weight. This may be linked to the viscosity provided by $\mathrm{CE}$ which is governed by the chain length of backbone (molecular weight). However, for all $\mathrm{CE}$ studied, when the molar substitution increased, the water retention capacity of the mortar slightly decreased. Moreover, the rheological study showed that consistency variations are not always responsible for water retention evolutions.

\section{Conclusions}

Based upon this study, it can be concluded that gradual effects on mortar water retention were clearly observed as a function of cellulose ether chemistry. One of the main conclusions of this study is that the structural parameters are essential. The results demonstrated that the molecular weight is crucial to control water retention and mortar consistency. It was noted that, as molecular weight increased, the yield stress was diminished, the consistency was increased and the water retention was improved. On the contrary, the molar substitution (relative to hydroxyethoxyl/hydroxypropoxyl content) seems to have a lower impact on the water retention of admixed mortars. Nevertheless, the water retention was improved for low molar substitutions of the $\mathrm{CE}$.

An important conclusion, related to the water retention mechanisms, is that the rheological properties of the mortar are one of the key properties. From experimental results, for mixtures evaluated at constant water/cement and constant admixture amount, mortar water retention evolved, in general, in the same manner as its consistency. This was observed within a given group in which only one structural parameter was changed. However, for some cellulose ethers this tendency was not respected. Moreover, for starch ether, the opposite behaviour was noticed. Hence, the viscosity of the fresh material is not the only parameter responsible for good water retention capacities.

\section{Acknowledgements}

The author would like to acknowledge all the industrial and academic CEReM members for their financial and technical support (http://extranet.cstb.fr/).

\section{References}

[1] V.S. Ramachandran, Concrete Admixtures Handbook (Second Edition), Noyes Publications (1995).

[2] K.H. Khayat, Viscosity-enhancing admixtures for cement-based materials - an overview, Cem. Concr. Comp. 20 (2-3) (1998).

[3] L. Bertrand, S. Maximilien and R. Guyonnet, Wedge Splitting Test: a test to measure the polysaccharide influence on adhesion of mortar on its substrate, Proceedings of the 11th International Congress on Polymers in Concrete, Berlin, Germany (2004).

[4] V.A. Ghio, P.J.M. Monteiro and L.A. Demsetz, The rheology of fresh cement paste containing polysaccharide gums, Cem. Concr. Res. 24 (2) (1994).

[5] N.K. Singh, P.C. Mishra, V.K. Singh and K.K. Narang, Effects of hydroxyethyl cellulose and oxalic acid on the properties of cement, Cem. Concr. Res. 33 (9) (2003).

[6] A. Peschard, A. Govin, P. Grosseau, B. Guilhot and R. Guyonnet, Effect of polysaccharides on the hydration of cement paste at early ages, Cem. Concr. Res. 34 (11) (2004).

[7] B. Ruot, T. Goto and J. Pourchez, Some aspects of cellulose ethers and latexes influence on the properties of cement-based materials - examples of results obtained within the CEReM, Proceedings of the VII SBTA ( $7^{\circ}$ Symposio Brasileiro De Tecnologia Das Argamassas) (2007). 
[8] A.M. Betioli, P.J.P. Gleize, D.A. Silva, V.M. John and R.G. Pileggi, Effect of HMEC on the consolidation of cement pastes: isothermal calorimetry versus oscillatory rheometry, Cem. Concr. Res. 39 (5) (2009).

[9] J. Pourchez, A. Peschard, P. Grosseau, R. Guyonnet, B. Guilhot and F. Vallée, HPMC and HEMC influence on cement hydration, Cem. Concr. Res. 36 (2) (2006).

[10] J. Pourchez, P. Grosseau, R. Guyonnet and B. Ruot, HEC influence on cement hydration measured by conductometry, Cem. Concr. Res. 36 (9) (2006).

[11] K.M. Green, M.A. Carter, W.D. Hoff and M.A. Wilson, The effects of lime and admixtures on the water-retaining properties of cement mortars, Cem. Concr. Res. 29 (11) (1999).

[12] M. Lachemi, K.M.A. Hossain, V. Lambros, P.-C. Nkinamubanzi and N. Bouzoubaâ, Performance of new viscosity modifying admixtures in enhancing the rheological properties of cement paste, Cem. Concr. Res. 34 (2) (2004).

[13] H. Paiva, L.M. Silva, J.A. Labrincha and V.M. Ferreira, Effects of a water-retaining agent on the rheological behaviour of a single-coat render mortar, Cem. Concr. Res. 36 (7) (2006).

[14] M.U.K. Afridi, Y. Ohama, M.Z. Iqbal and K. Demura, Water retention and adhesion of powdered and aqueous polymer-modified mortars, Cem. Concr. Comp. 17 (2) (1995).

[15] C.M. Capener, Properties of modern rendering systems based on mineral binders modified by organic admixtures, Concrete Repair, Rehabilitation and Retrofitting Ii (2009).

[16] J.-L. Wolf. Valorisation des amidons et des amidons modifiés comme adjuvants des mortiers et des bétons. PhD Thesis. Institut National des Sciences Appliquées de Lyon (1996), $243 \mathrm{p}$.

[17] Y. Ohama, Polymer-based admixtures, Cem. Concr. Comp. 20 (2-3) (1998) (2-3).

[18] J. Pourchez. Aspects physico-chimiques de l'interaction des éthers de cellulose avec la matrice cimentaire. PhD Thesis. Ecole Nationale Supérieure des Mines de Saint-Etienne (2006), $285 \mathrm{p}$.

[19] A. Jenni, L. Holzer, R. Zurbriggen and M. Herwegh, Influence of polymers on microstructure and adhesive strength of cementitious tile adhesive mortars, Cem. Concr. Res. 35 (1) (2005).

[20] C.F. Ferraris and N.S. Martys, Relating fresh concrete viscosity measurements from different rheometers, J. Res. Natl. Inst. Stan. 108 (3) (2003).

[21] C.F. Ferraris, Measurement of the rheological properties of high performance concrete; state of the art report, J. Res. Natl. Inst. Stan. 104 (5) (1999).

[22] M.P. Seabra, H. Paiva, J.A. Labrincha and V.M. Ferreira, Admixtures effect on fresh state properties of aerial lime based mortars, Const. Build. Mater. 23 (2) (2009).

[23] M.P. Seabra, J.A. Labrincha and V.M. Ferreira, Rheological behaviour of hydraulic limebased mortars, J. Eur. Ceram. Soc. 27 (2-3) (2007).

[24] H. Paiva, L.P. Esteves, P.B. Cachim and V.M. Ferreira, Rheology and hardened properties of single-coat render mortars with different types of water retaining agents, Const. Build. Mater. 23 (2) (2009).

[25] EN 196-1. Methods of Testing Cement - Part 1: Determination of Strength (2006).

[26] NF EN 13139. Granulats pour mortiers - Spécifications des caractéristiques des granulats et fillers utilisés dans les mortiers (2003).

[27] EN 197-1. Cement. Part 1: Composition, Specification and Conformity Criteria for Common Cements (2001).

[28] R.L. Feller and M. Wilt, Evaluation of Cellulose Ethers for Conservation, Getty Conservation Institute (1990).

[29] S. Nilsson, L.-O. Sundelöf and B. Porsch, On the characterization principles of some technically important water soluble non-ionic cellulose derivatives, Carbohyd. Polym. 28 (3) (1995).

[30] C. Clasen and W.-M. Kulicke, Determination of viscoelastic and rheo-optical material functions of water-soluble cellulose derivatives, Prog. Polym. Sci. 26 (9) (2001). 
[31] Standard C1506-09, Standard test Method fo Water Retention of Hydraulic CementBased Mortars and Plasters, Am. Soc. Test. Mat. (2009).

[32] Standard DIN 18555-7, Testing of Mortars Containing Mineral Binders; Part 7: Determination of Water Retentivity of Freshly Mixed Mortar by the Filter Plate Method, Deutsches Institut für Normung (2000).

[33] S. Hucko, Hot climate render additive, Proceedings of the V SBTA (Simpósio Brasileiro De Tecnologia Das Argamassas), São Paulo, Brazil (2003).

[34] H.A. Barnes and Q.D. Nguyen, Rotating vane rheometry - a review, J. Non-Newton. Fluid 98 (1) (2001).

[35] A. Ait-Kadi, P. Marchal, L. Choplin, A.S. Chrissemant and M. Bousmina, Quantitative analysis of mixer-type rheometers using the Couette analogy, Can. J. Chem. Eng. 80 (6) (2002).

[36] A. Yahia and K.H. Khayat, Analytical models for estimating yield stress of highperformance pseudoplastic grout, Cem. Concr. Res. 31 (5) (2001).

[37] M. Nehdi and M.-A. Rahman, Estimating rheological properties of cement pastes using various rheological models for different test geometry, gap and surface friction, Cem. Concr. Res. 34 (11) (2004).

[38] W.M. Herschel and R. Bulkley, Measurements of consistency as applied to rubberbenzene solutions, Am. Soc. Test. Mat., Proc. 26 (1926).

[39] F. Larrard, C.F. Ferraris and T. Sedran, Fresh concrete: a Herschel-Bulkley material, Mat. Struct. 31 (7) (1998).

[40] P. Coussot and C. Ancey, Rhéophysique des pâtes et des suspensions, EDP Sci. (1999).

[41] C. Atzeni, L. Massidda and U. Sanna, Comparison between rheological models for portland cement pastes, Cem. Concr. Res. 15 (3) (1985).

[42] L. Nachbaur, J.C. Mutin, A. Nonat and L. Choplin, Dynamic mode rheology of cement and tricalcium silicate pastes from mixing to setting, Cem. Concr. Res. 31 (2) (2001).

[43] NF DTU 26.1. Travaux d'enduits de mortiers (2008).

[44] Z. Toutou, N. Roussel, C. Lanos, Y. Mélinge, P. Monnet, A. Pantet and R. Le Roy, Rhéologie des suspensions à matrice cimentaire. Approche expérimentale multi-échelle, Rev. Eur. Génie Civ. 9 (3) (2005).

[45] H.M. Nguyen, Comportement rhéologique des suspensions concentrées, Master Research Report, INSA Rennes (2003) (63 p.).

[46] A. Leemann and F. Winnefeld, The effect of viscosity modifying agents on mortar and concrete, Cem. Concr. Comp. 29 (5) (2007).

[47] K.H. Khayat and A. Yahia, Effect of welan gum-high-range water reducer combinations on rheology of cement grout, ACI Mater. J. 94 (5) (1997).

[48] A. Yahia and K. Khayat, Applicability of rheological models to high-performance grouts containing supplementary cementitious materials and viscosity enhancing admixture, Mater. Struct. 36 (6) (2003).

[49] M. Sonebi, Rheological properties of grouts with viscosity modifying agents as diutan gum and welan gum incorporating pulverised fly ash, Cem. Concr. Res. 36 (9) (2006).

[50] V. Kontogiorgos, H. Vaikousi, A. Lazaridou and C.G. Biliaderis, A fractal analysis approach to viscoelasticity of physically cross-linked barley [beta]-glucan gel networks, Coll. Surf. B: Biointerf. 49 (2) (2006).

[51] S.M.C. Silva, F.V. Pinto, F.E. Antunes, M.G. Miguel, J.J.S. Sousa and A.A.C.C. Pais, Aggregation and gelation in hydroxypropylmethyl cellulose aqueous solutions, J. Colloid Interf. Sci. 327 (2) (2008).

[52] A. Izaguirre, J. Lanas and J.I. Álvarez, Behaviour of a starch as a viscosity modifier for aerial lime-based mortars, Carbohydr. Polym. 80 (1) (2010). 
Figures

(a)

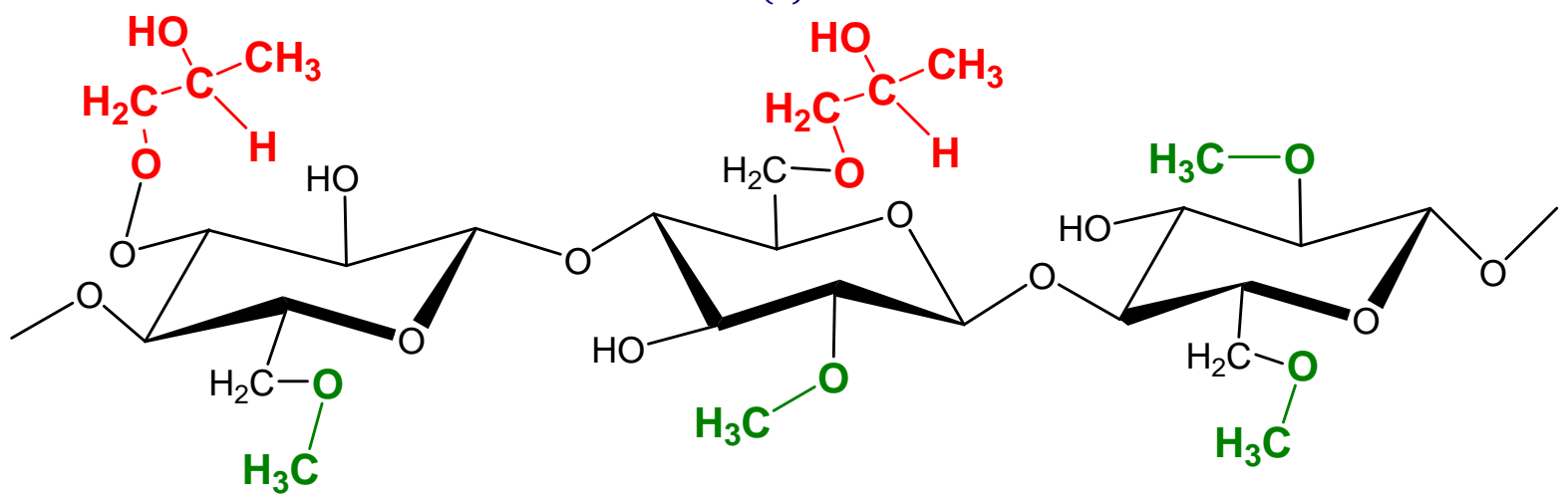

(b)

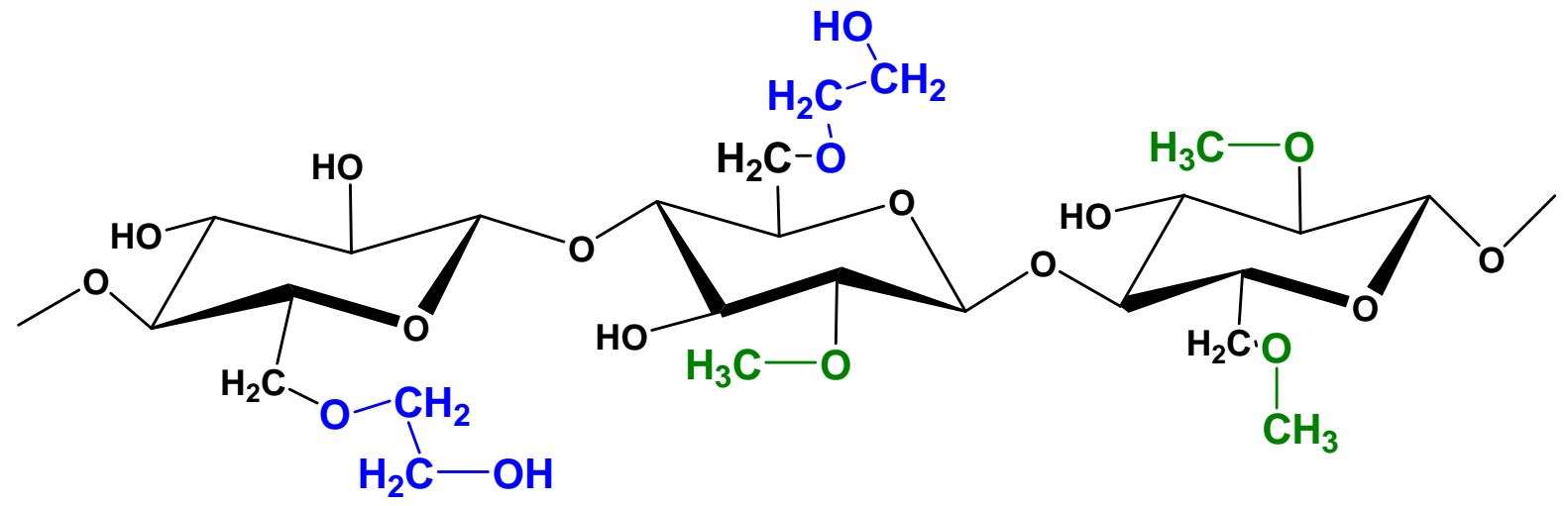

(c)

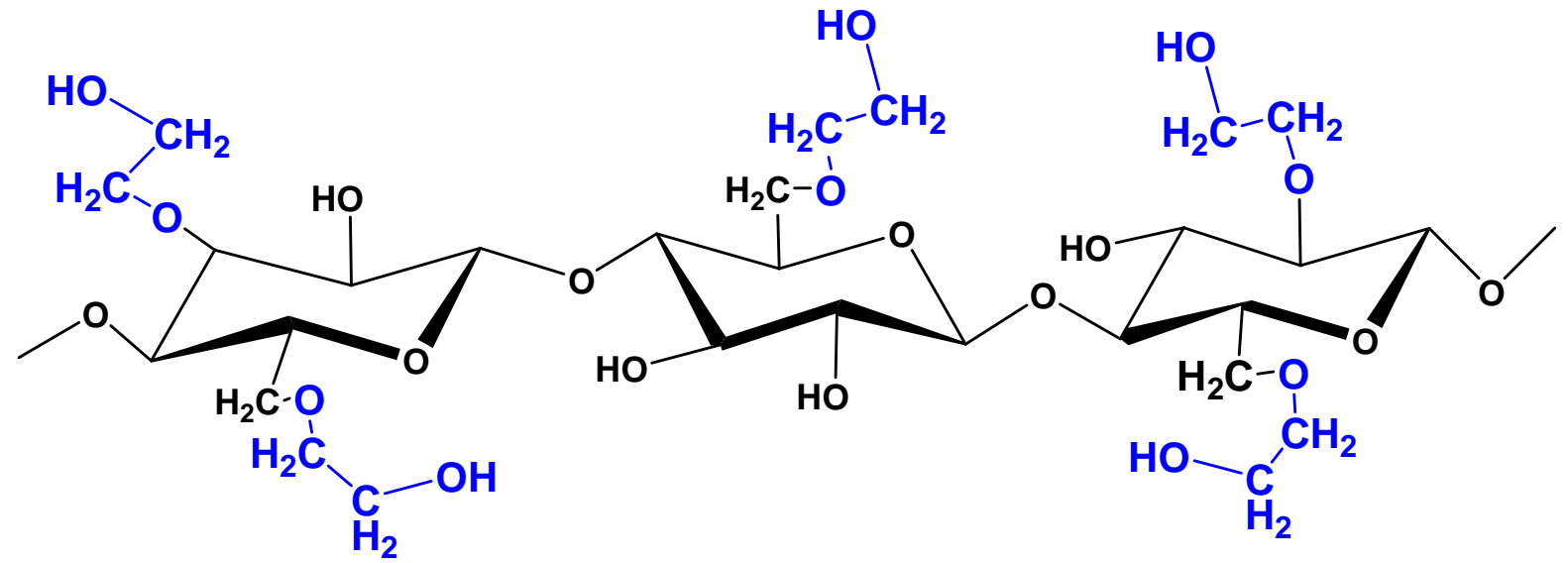

Figure 1: Structure of cellulose ethers [(a): HPMC, (b): HEMC, (c): HEC]. Substituent positions are arbitrary; they may differ slightly from one molecule to another. 


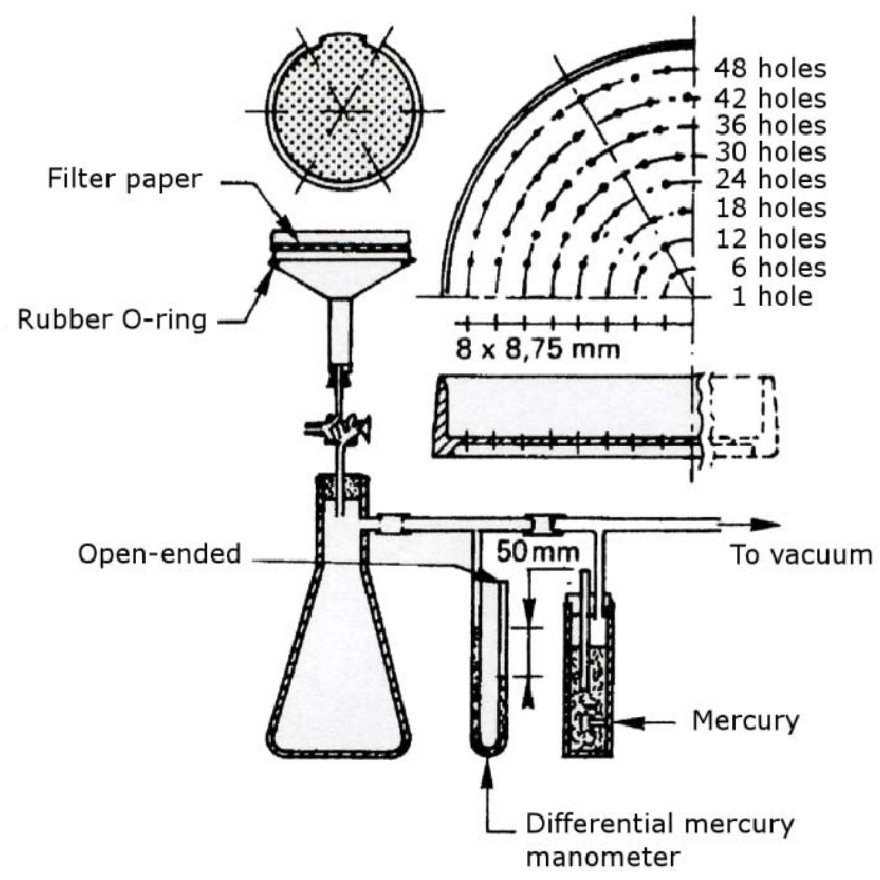

Figure 2: Experimental device to measure water retention with ASTM C91 standard.

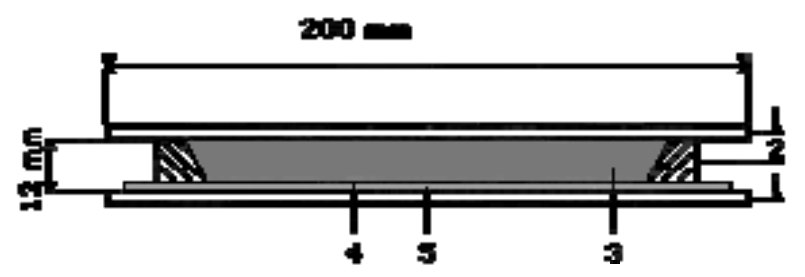

Figure 3: DIN 18555-7 test arrangement for determining the water retention of freshly-mix ed mortars (1: two plastic plates, 2: conical plastic ring, 3: mortar, 4: filter paper, 5: nonwoven tissue).

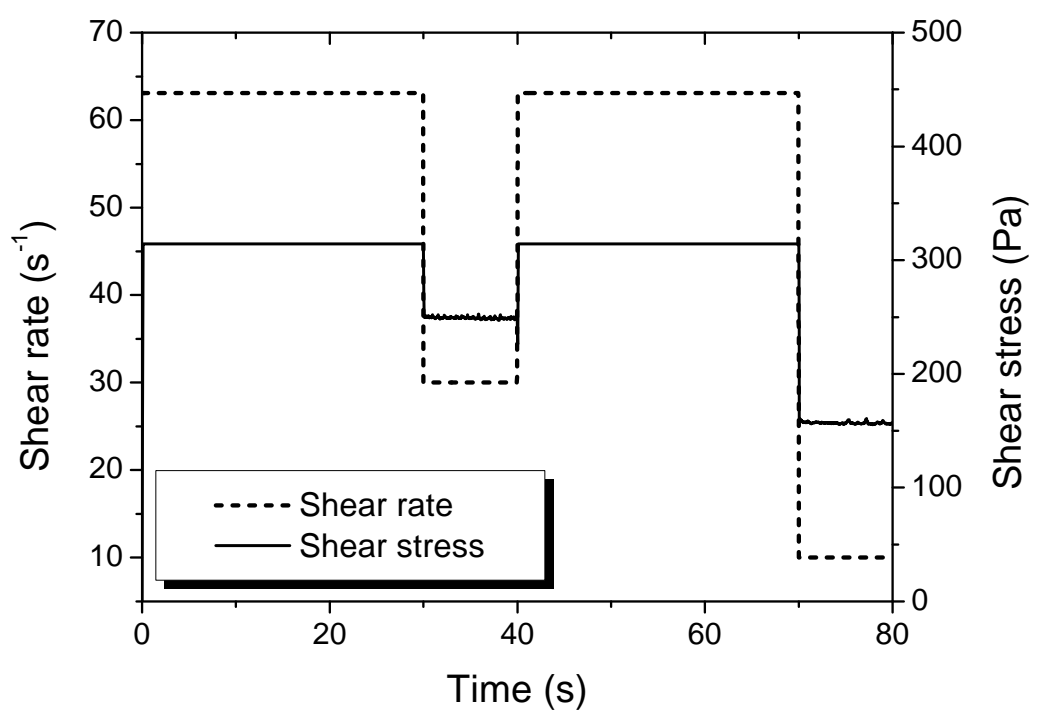

Figure 4: Example of a resuspension sequence for the HEMC C4: resuspension stage at $63.1 \mathrm{~s}^{-1}$ during $30 \mathrm{~s}$ followed by the studied shear rate ( $30 \mathrm{~s}^{-1}$ during $10 \mathrm{~s}$ and $10 \mathrm{~s}^{-1}$ during $\left.10 \mathrm{~s}\right)$. 


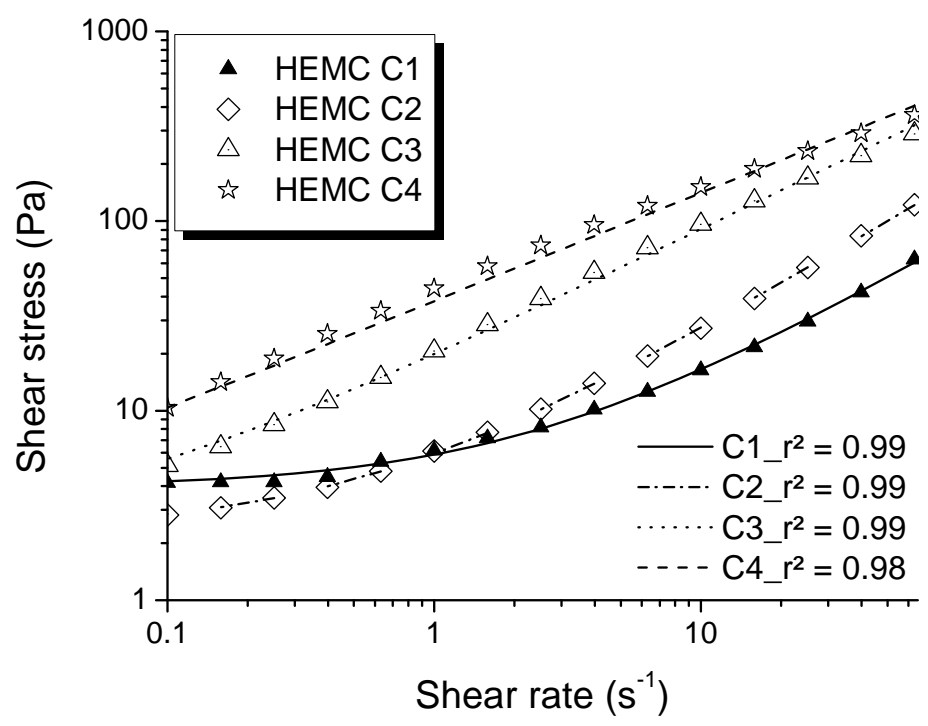

Figure 5: Fitted curves with Herschel-Bulkley model for HEMC C admixed mortars.

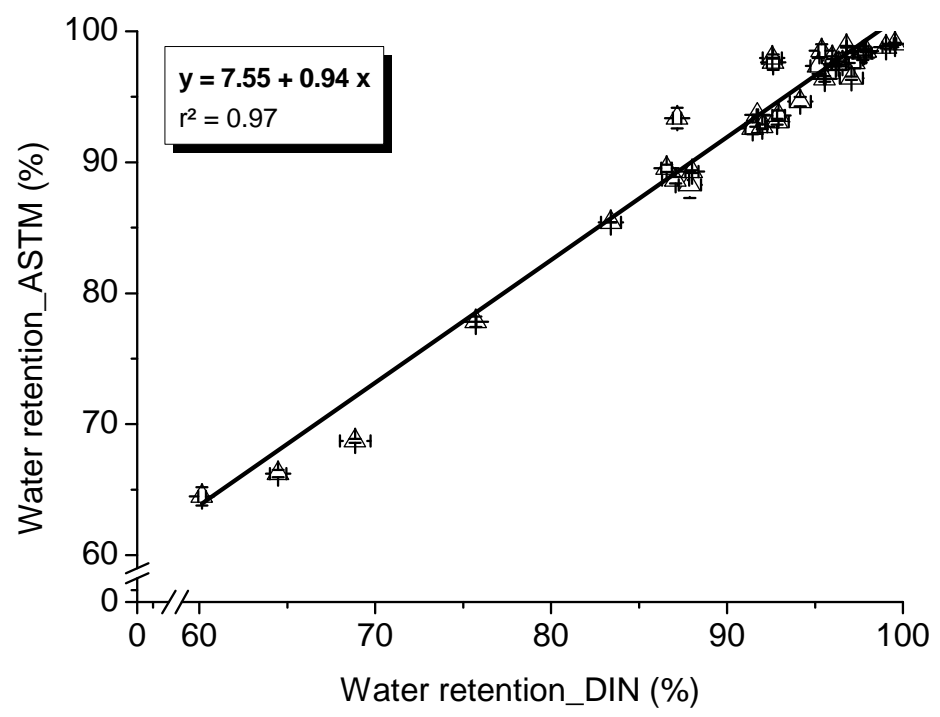

Figure 6: Comparison between the DIN and the ASTM methods for the determination of the water retention of freshly-mixed mortars admixed with CE and starch derivatives. 


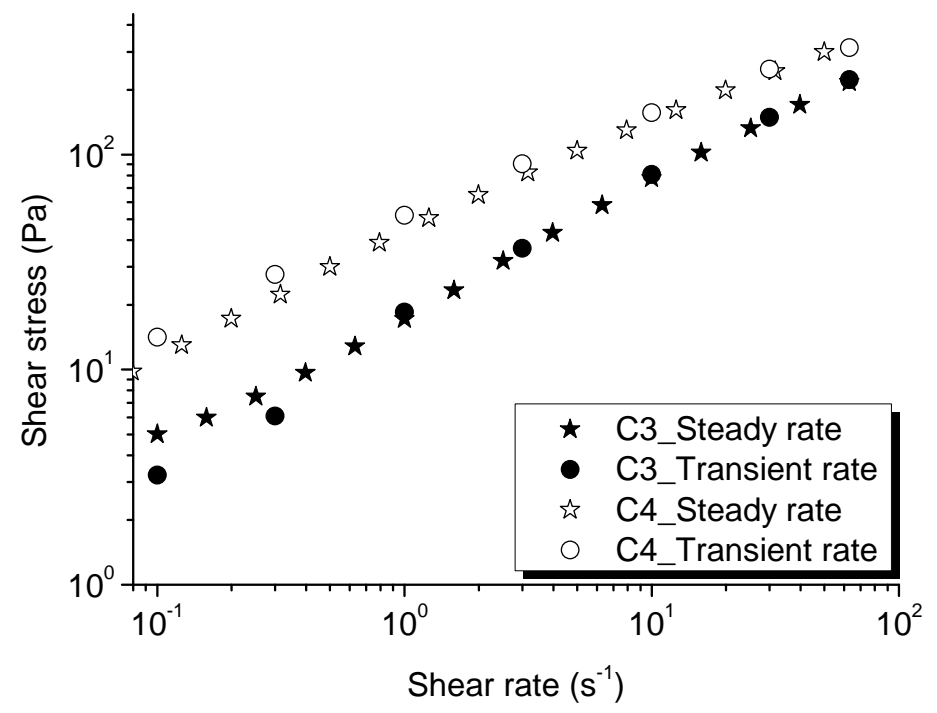

Figure 7: Rheograms in steady-state regime for admixed mortars containing HEMC C3 or HEMC C4 with and without resuspension steps, performed with vane geometry.

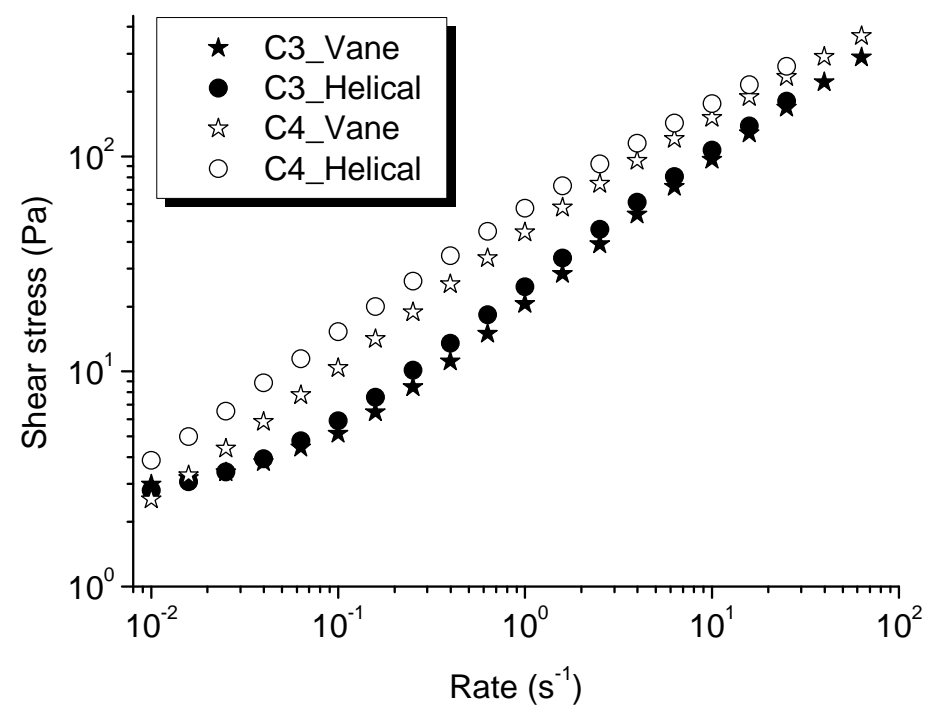

Figure 8: Rheograms for admixed mortars containing HEMC C3 or HEMC C4 for two geometries: the vane and the helical geometry. 


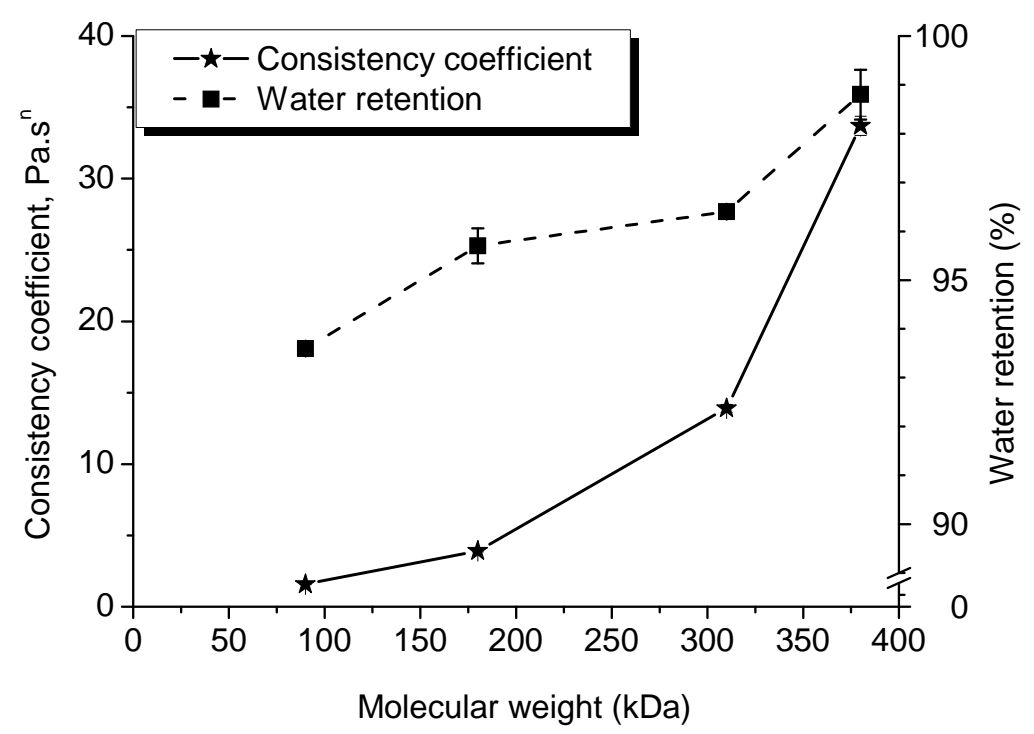

Figure 9: Effect of HEMC C molecular weight on consistency coefficient and water retention of admixed mortars.

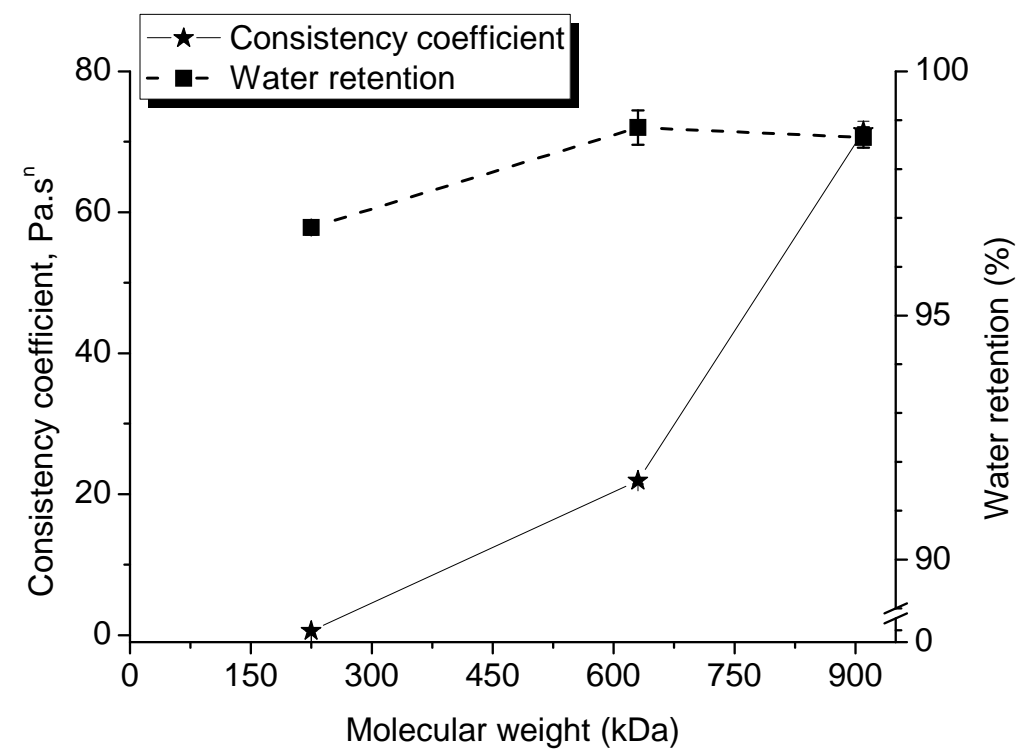

Figure 10: Effect of HPMC J molecular weight on consistency coefficient and water retention of admixed mortars. 


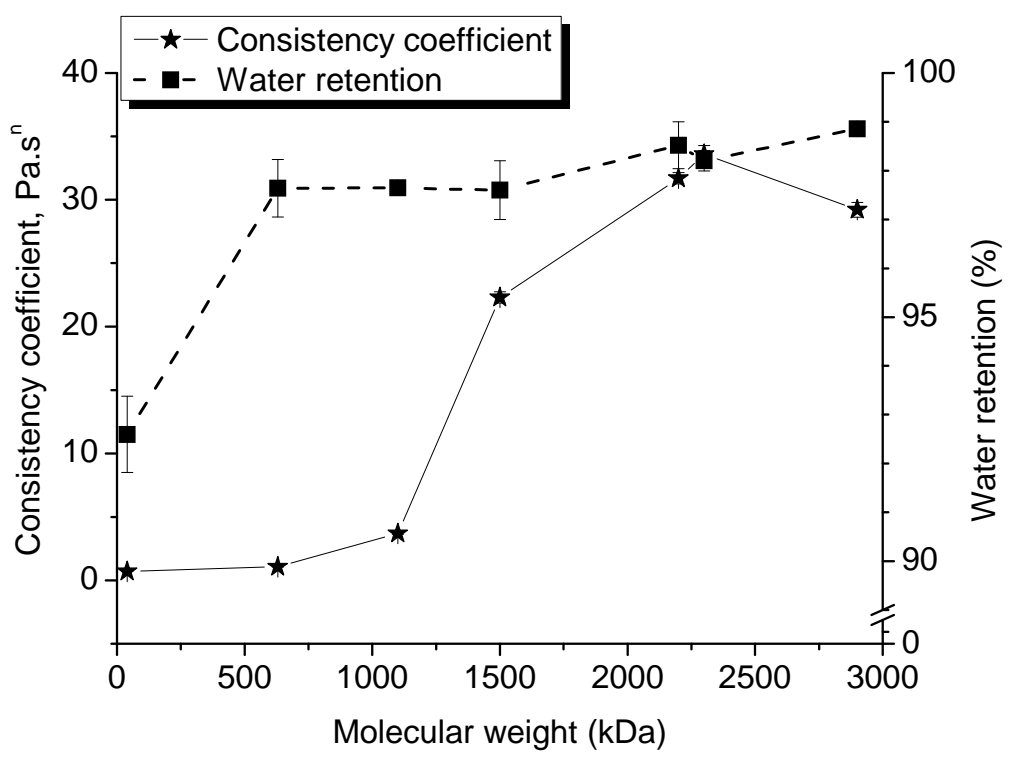

Figure 11: Effect of HEC N molecular weight on consistency coefficient and water retention of admixed mortars.

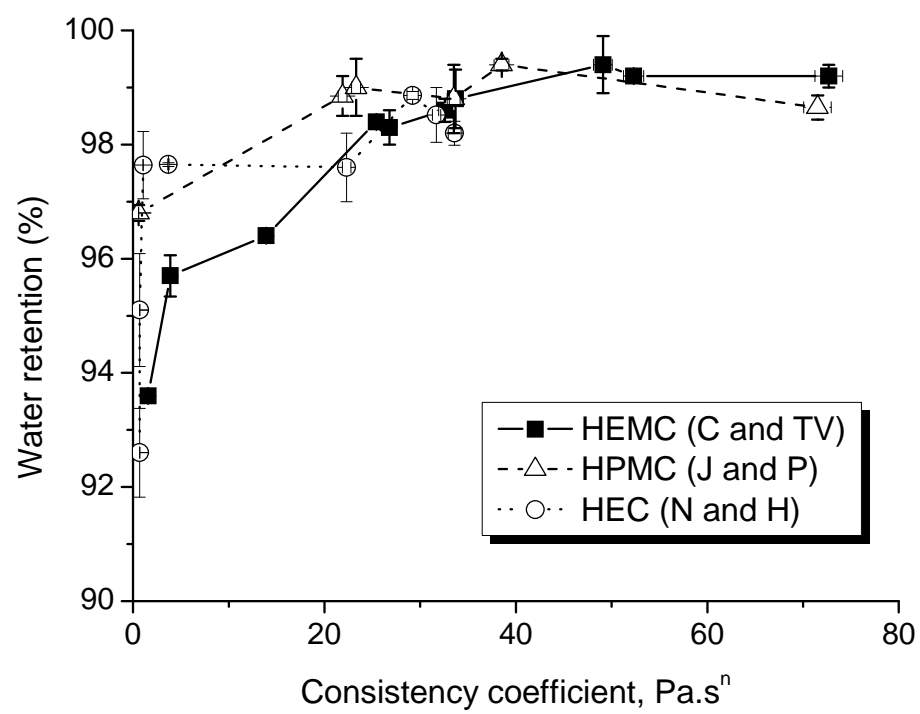

Figure 12: Water retention as a function of the consistency coefficient of CE-admixed mortars. 


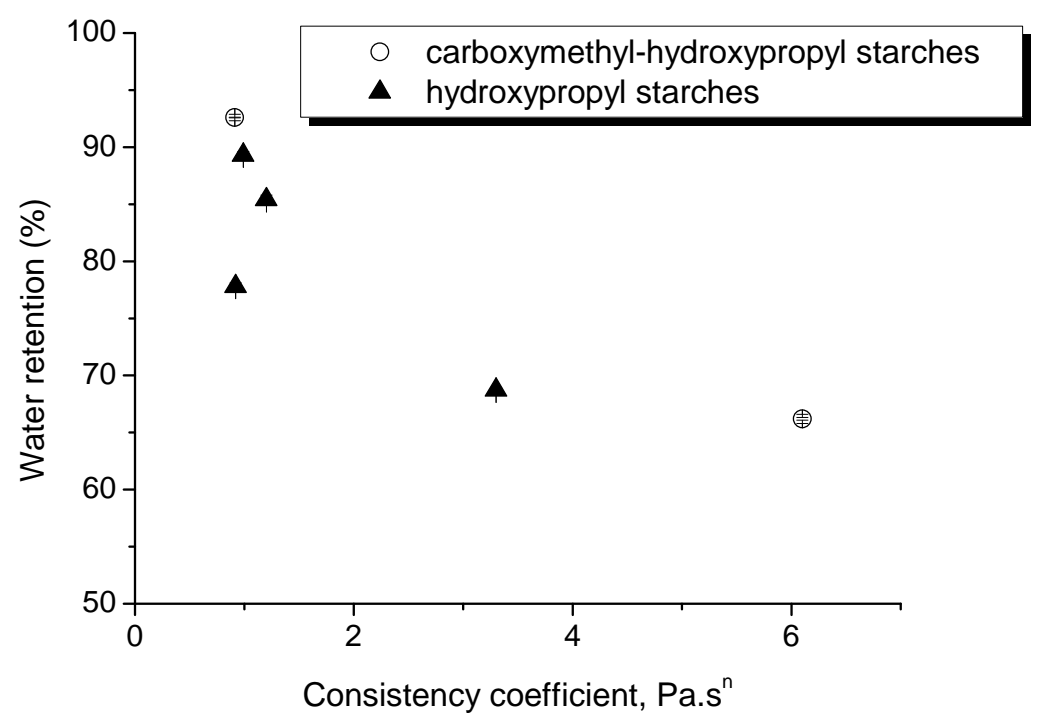

Figure 13: Effect of starch ethers on consistency coefficient and water retention of SE-admixed mortars.

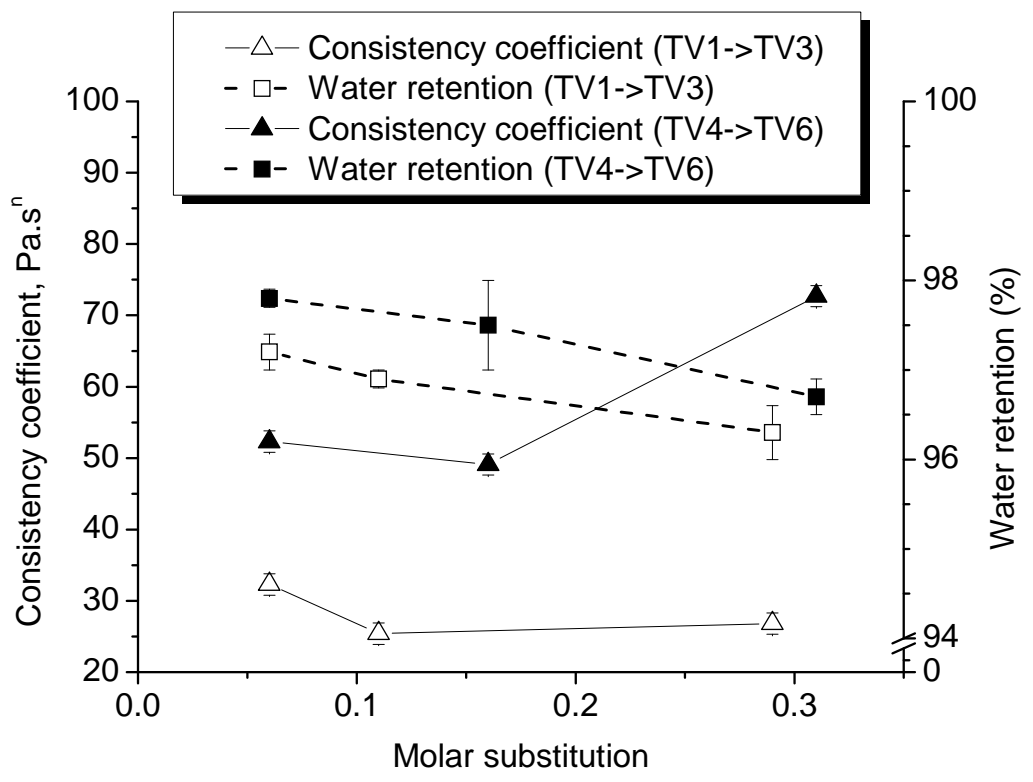

Figure 14: Effect of HEMC TV molar substitution on consistency coefficient and water retention of admixed mortars. 
Cement and Concrete Research, 2010, 41(1),46-55, doi:10.1016/j.cemconres.2010.09.004

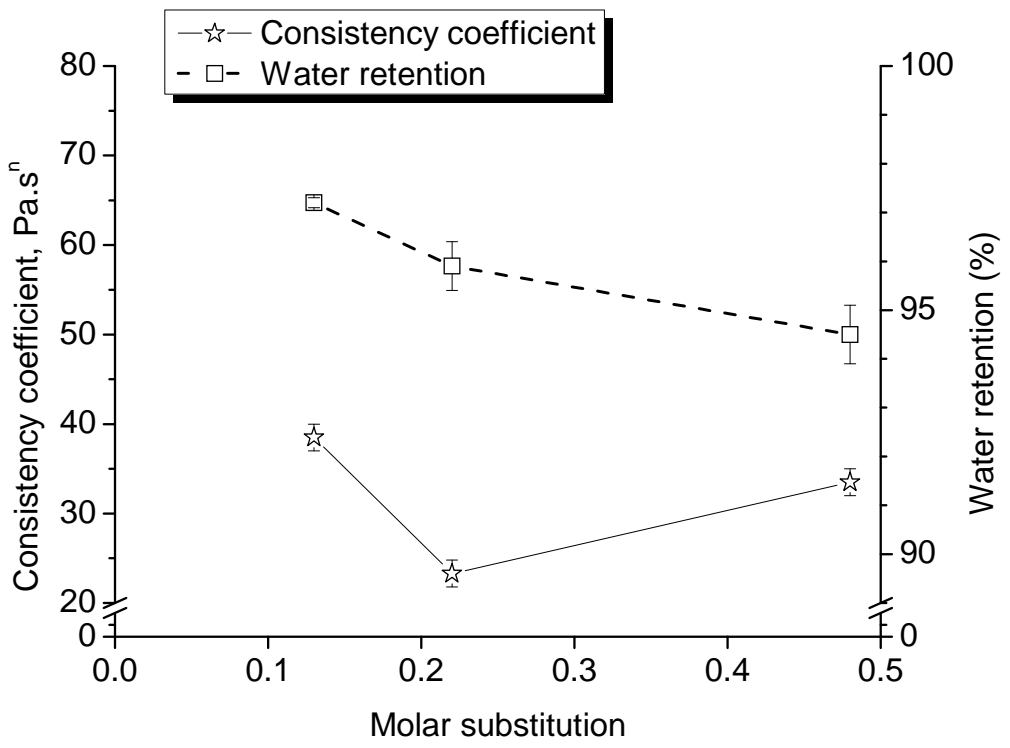

Figure 15: Effect of HPMC P molar substitution on consistency coefficient and water retention of admixed mortars. 
Cement and Concrete Research, 2010, 41(1),46-55, doi:10.1016/j.cemconres.2010.09.004

\section{Tables}

Table 1: CEReM mortar formulation.

\begin{tabular}{|l|c|c|c|c|c|}
\hline Component & Cement & Sand & $\mathrm{CaCO}_{3}$ & Admixture $^{a}$ & ${\text { Water mQ (Millipore } 囚)^{a}}^{a}$ \\
\hline$\%$ wt of dry mixture & $30 \%$ & $65 \%$ & $5 \%$ & $0.27 \%$ & $30 \%$ \\
\hline
\end{tabular}

a In addition of dry mixture (composed of cement, sand and $\mathrm{CaCO}_{3}$ )

Table 2: Chemical and phase compositions of the investigated cement.

\begin{tabular}{|c|c|}
\hline \multicolumn{2}{|c|}{ Chemical composition (\% wt) } \\
\hline Oxides & $X R F$ \\
\hline $\mathrm{CaO}$ & $66.3 \pm 0.2$ \\
\hline $\mathrm{SiO}_{2}$ & $22.3 \pm 0.1$ \\
\hline $\mathrm{Al}_{2} \mathrm{O}_{3}$ & $3.40 \pm 0.01$ \\
\hline $\mathrm{SO}_{3}$ & $3.04 \pm 0.03$ \\
\hline $\mathrm{Fe}_{2} \mathrm{O}_{3}$ & $2.87 \pm 0.03$ \\
\hline $\mathrm{MgO}$ & $0.99 \pm 0.01$ \\
\hline $\mathrm{P}_{2} \mathrm{O}_{5}$ & $0.24 \pm 0.01$ \\
\hline $\mathrm{TiO}_{2}$ & $0.18 \pm 0.18$ \\
\hline $\mathrm{K}_{2} \mathrm{O}$ & $0.04 \pm 0.04$ \\
\hline $\mathrm{MnO}$ & $0.016 \pm 0.001$ \\
\hline \multicolumn{2}{|c|}{ Phase composition (\% wt) } \\
\hline Phases & XRF (Bogue) \\
\hline$C_{3} S$ & $64.3 \pm 0.8$ \\
\hline$C_{2} S$ & $15.5 \pm 0.3$ \\
\hline$C_{3} A$ & $4.2 \pm 0.1$ \\
\hline$C_{4} A F$ & $8.7 \pm 0.1$ \\
\hline Sulfates & $3.04 \pm 0.03$ \\
\hline
\end{tabular}


Cement and Concrete Research, 2010, 41(1),46-55, doi:10.1016/j.cemconres.2010.09.004

Table 3: Cellulose ethers (HEMC, HPMC, HEC) and starch ethers (SE) used in this work.

\begin{tabular}{|c|c|c|c|c|c|}
\hline HEMC & $\bar{M}_{W}(k D a)$ & Methoxy group ${ }^{a}\left(\% \mathrm{OCH}_{3}\right)$ & $D S$ & Hydroxyethyl group ${ }^{a}\left(\% \mathrm{OC}_{2} \mathrm{H}_{4} \mathrm{OH}\right)$ & $M S$ \\
\hline$C 1$ & 90 & 28.4 & 1.8 & 4.7 & 0.15 \\
\hline C2 & 180 & 27.4 & 1.7 & 4.8 & 0.15 \\
\hline$C_{3}$ & 310 & 27.4 & 1.7 & 4.8 & 0.15 \\
\hline$C_{4}$ & 380 & 27.4 & 1.7 & 4.8 & 0.15 \\
\hline$T V 1$ & 350 & 29.3 & 1.8 & 1.9 & 0.06 \\
\hline TV2 & 350 & 29.0 & 1.8 & 3.2 & 0.11 \\
\hline$T V_{3}$ & 350 & 27.6 & 1.8 & 8.9 & 0.29 \\
\hline $\mathrm{TV}_{4}$ & 390 & 29.3 & 1.8 & 1.4 & 0.06 \\
\hline TV5 & 410 & 28.4 & 1.8 & 3.6 & 0.16 \\
\hline TV6 & 410 & $27 \cdot 5$ & 1.8 & 6.8 & 0.31 \\
\hline HPMC & $\bar{M}_{W}(k D a)$ & Methoxy group ${ }^{a}\left(\% \mathrm{OCH}_{3}\right)$ & $D S$ & Hydroxypropyl group ${ }^{a}\left(\% \mathrm{OC}_{3} \mathrm{H}_{6} \mathrm{OH}\right)$ & $M S$ \\
\hline$J_{1}$ & 225 & 28.2 & 1.8 & 2.98 & 0.1 \\
\hline$J_{2}$ & 630 & 28.2 & 1.8 & 2.98 & 0.1 \\
\hline$J_{3}$ & 910 & 28.2 & 1.8 & 2.98 & 0.1 \\
\hline$P 1$ & 255 & 28.4 & 1.8 & 3.0 & 0.13 \\
\hline$P_{2}$ & 265 & 27.2 & 1.8 & $5 \cdot 0$ & 0.22 \\
\hline$P_{3}$ & 245 & 24.5 & 1.7 & 10.2 & 0.48 \\
\hline$H E C$ & $\bar{M}_{W}(k D a)$ & & & Hydroxyethyl group ${ }^{a}\left(\% \mathrm{OC}_{2} \mathrm{H}_{4} \mathrm{OH}\right)$ & $M S$ \\
\hline$H 1$ & 45 & & & $45 \cdot 3$ & 1.9 \\
\hline$N 1$ & 40 & & & 56.0 & 2.5 \\
\hline N2 & 630 & & & 56.0 & 2.5 \\
\hline$N_{3}$ & 1100 & & & 56.0 & 2.5 \\
\hline$N_{4}$ & 1500 & & & 56.0 & 2.5 \\
\hline N5 & 2200 & & & 56.0 & 2.5 \\
\hline N6 & 2300 & & & 56.0 & 2.5 \\
\hline$N_{7}$ & 2900 & & & 56.0 & 2.5 \\
\hline
\end{tabular}


Cement and Concrete Research, 2010, 41(1),46-55, doi:10.1016/j.cemconres.2010.09.004

\begin{tabular}{|c|c|c|c|c|}
\hline \multirow{2}{*}{$S E$} & \multirow{2}{*}{$\bar{M}_{W}(k D a)$} & \multirow{2}{*}{ Amylopectin / amylose ratio ${ }^{a}$} & \multicolumn{2}{|c|}{ Degrees of polymerization $^{a}$} \\
\hline & & & Amylose & Amylopectin \\
\hline$M 1$ & 860 & $80 / 20$ & 4000 & 2000000 \\
\hline M2 & 850 & $80 / 20$ & 4000 & 2000000 \\
\hline M3 & 880 & $80 / 20$ & 4000 & 2000000 \\
\hline M4 & 830 & $80 / 20$ & 4000 & 2000000 \\
\hline$L 2$ & 780 & $80 / 20$ & 4000 & 2000000 \\
\hline$L_{3}$ & 850 & - & - & - \\
\hline
\end{tabular}

${ }^{a}$ Informations provided by the manufacturer. 
Cement and Concrete Research, 2010, 41(1),46-55, doi:10.1016/j.cemconres.2010.09.004

Table 4: Rheological parameters determined using the Herschel-Bulkley model.

\begin{tabular}{|c|c|c|c|c|}
\hline Admixture & $\begin{array}{l}\text { Yield stress } \\
\quad(\mathrm{Pa})\end{array}$ & $\begin{array}{c}\text { Consistency } \\
\text { Coefficient }\left(\text { Pa.s }{ }^{n}\right)\end{array}$ & $\begin{array}{c}\text { Flow behaviour } \\
\text { index }\end{array}$ & Water retention (\%) \\
\hline$H E M C C 1$ & $5 \cdot 4$ & 1.6 & 0.86 & 93.6 \\
\hline HEMC C2 & 2.5 & $3 \cdot 9$ & 0.79 & $95 \cdot 7$ \\
\hline $\mathrm{HEMC} \mathrm{C}_{3}$ & 2.6 & 13.9 & 0.70 & 96.4 \\
\hline $\mathrm{HEMCC}_{4}$ & 2.0 & 33.7 & 0.59 & 98.8 \\
\hline$H P M C J 1$ & 4.2 & 0.6 & 0.99 & 96.8 \\
\hline HPMC J2 & 0.6 & $27 \cdot 9$ & 0.62 & 98.6 \\
\hline${ }^{H P M C} J_{3}$ & $\approx 0$ & 71.5 & 0.47 & 98.9 \\
\hline$H E C H 1$ & $\approx 0$ & 0.7 & 0.97 & 95.1 \\
\hline$H E C N 1$ & $\approx 0$ & 0.7 & 0.99 & 92.6 \\
\hline HEC N2 & 0.6 & 1.1 & 0.90 & 97.6 \\
\hline $\mathrm{HECN}_{3}$ & 1.5 & 3.7 & 0.73 & $97 \cdot 7$ \\
\hline $\mathrm{HECN}_{4}$ & $\approx 0$ & 22.3 & 0.58 & 97.6 \\
\hline HEC N5 & 0.5 & 31.7 & 0.58 & 98.5 \\
\hline HEC N6 & 1.9 & 33.6 & 0.56 & 98.2 \\
\hline $\mathrm{HECN}_{7}$ & 0.6 & 29.2 & 0.67 & 98.8 \\
\hline$S E M 1$ & $\approx 0$ & 0.91 & 0.89 & 92.6 \\
\hline$S E M 2$ & $\approx 0$ & 1.2 & 0.86 & 85.4 \\
\hline$S E M_{3}$ & $\approx 0$ & 0.92 & 0.95 & 77.8 \\
\hline $\mathrm{SE} \mathrm{M}_{4}$ & $\approx 0$ & 6.1 & 0.48 & 66.2 \\
\hline$S E L 2$ & 6.1 & $3 \cdot 3$ & 0.66 & 68.7 \\
\hline$S E L_{3}$ & $\approx 0$ & 0.99 & 0.88 & 89.3 \\
\hline Neat cement & 5.4 & 0.4 & 0.64 & 64.5 \\
\hline
\end{tabular}

